\title{
Exploring amazonian fats and oils blends by computational predictions of solid fat content
}

\author{
Moisés Teles dos Santos*, Pablo Morgavi and Galo A.C. Le Roux \\ Department of Chemical Engineering, University of São Paulo, Av. Prof. Luciano Gualberto, 380, 05508-900, São Paulo, Brazil
}

Received 3 August 2017 - Accepted 8 October 2017

\begin{abstract}
The Amazon region has richness of oleaginous plants that have attracted attention due to its unique properties. Integrating local communities in an economic chain of valorization of fats/oils can enhance the social dimension of local oleaginous industry sustainability. Given the large diversity of raw materials and the possibility to mix them in different proportions, an experimental effort must be done to evaluate the physical properties of such feedstocks. In this context, the development of computational tools able to estimate physical properties based on rigorous thermodynamic models can orient the experimental efforts thorough the mixtures of fats and oils most promising. The evaluation of the melting curves of nine Amazonian oils and fats is done by using thermodynamic modeling of the solid-liquid equilibrium and optimization tools. The binary blends of different raw materials were also evaluated. An average absolute error of $4.5^{\circ} \mathrm{C}$ was observed for the melting point and an absolute error of $3.8 \%$ was observed for the Solid Fat Content predictions over different temperatures and blends composition.
\end{abstract}

Keywords: thermodynamics / optimization / solid fat content / Amazonian oils / modeling

Résumé - Exploration de mélanges de graisses et d'huiles amazoniennes par prédiction informatique de la teneur en matières grasses solides. La région amazonienne est riche en plantes oléagineuses qui ont attiré l'attention en raison de leurs propriétés uniques. L'intégration des communautés locales dans une chaîne économique de valorisation des graisses / huiles peut renforcer la dimension sociale de la durabilité de l'industrie oléagineuse locale. Compte tenu de la grande diversité des matières premières et de la possibilité de les mélanger dans des proportions différentes, un effort expérimental doit être fait pour évaluer les propriétés physiques de ces matières premières. Dans ce contexte, le développement d'outils informatiques capables d'estimer les propriétés physiques à partir de modèles thermodynamiques rigoureux permet d'orienter les efforts expérimentaux sur les mélanges de graisses et d'huiles les plus prometteurs. L'évaluation des courbes de fusion de neuf huiles et graisses amazoniennes est réalisée en utilisant la modélisation thermodynamique de l'équilibre solide-liquide et des outils d'optimisation. Les mélanges binaires de différentes matières premières ont également été évaluées. Une erreur absolue moyenne de $4,5^{\circ} \mathrm{C}$ a été observée pour le point de fusion et une erreur absolue de $3,8 \%$ a été observée pour les prédictions de teneur en matière grasse solide, et ce pour différentes températures et compositions de mélanges.

Mots clés : thermodynamique / optimisation / teneur en matières grasses solides / huiles amazoniennes / modélisation

\section{Introduction}

Brazil has a large variability in vegetable oils and natural fats, due to its biodiversity in a continental territory with different climate zones, rainfall and soil properties. The Amazon regions, for instance, has richness of vegetable species and among them oleaginous plants have attracted attention due to their unique properties. Dozens of different

*Correspondence: moises.teles@usp.br oleaginous species have been studied aiming at identifying their chemical composition and physical properties, such as buriti pulp oil (Mauritia flexuosa Mart.), tucumã pulp and kernel oils (Astrocarium vulgare Mart.), rubber seed oil (Hevea brasiliensis), passion fruit oil (Passiflora edulis), ucuúba butter (Virola surinamensis), pracaxi seeds oil (Pentaclethra macroloba), cupuassu fat (Theobroma grandiflorum) and babassu oil (Attalea speciosa) (Bezerra et al., 2017; Pardauil et al., 2017). Also, other regions are rich in oleaginous species, such as macauba (Acrocomia aculeata) in 
central west region (César et al., 2015), different species in Brazilian Atlantic forest (Coutinho et al., 2016) and in the semi-arid region of northeast Brazil (Pinho et al., 2009). These resources show a large variability in oil content, fatty acids profile and productivity.

Beyond the potential of these feedstocks for the biodiesel industry, they can be also explored to boost innovative sectors in the food, pharmaceutical and cosmetic industry (Teles dos Santos et al., 2014). Those industries have searched for functional formulations, to respond to market demands in terms of enhanced and multifunctional properties. The cosmetic industry, for example, has shifted from pure beauty-related products to formulations with additional attributes, such as healthy, natural and exotic raw materials and sustainable production processes. The food industry, in turn, has claimed for functional foods, defined as foods in which concentrations of one or more ingredients have been modified to enhance their contributions to a healthful diet (Bruin and Jongen, 2003). Also, much attention has been devoted to cocoa butter equivalents, alternatives and replacers (Lipp and Anklam, 1998; Jahurul et al., 2013).

In many uses, such as in vegetable creams, margarines, chocolates, and special fats for confectionery, the solid fat content plays a major role. Indeed, pure fats and oils often do not have adequate physicochemical properties for direct use in their natural state, thus needing combining them with other fats and oils or modifying them by enzymatic or chemical interesterification.

However, intensive experimental evaluation of physicochemical properties of such diversity in raw materials and blends is time consuming and costly. Computational simulations of vegetable oils/fats mixtures coupled with thermodynamic modeling and optimization tools can be useful to prospect new feedstocks usage in the development of products.

\section{Background in solid-liquid equilibrium of fats and oils}

Fats and oils tend to crystallize in different solid forms according to the temperature. This solid-liquid behavior sets most of the applicability of different fats and oils and several studies have been done to model the solid-liquid equilibrium in triacylglycerol systems. The solid-liquid equilibrium of fats and oils is complex and imposes several challenges to describe the multiple solid phases that can be formed (Hjorth et al., 2014; Maximo et al., 2014). Thermodynamic approaches for multicomponent mixtures can be found in the works of Won (1993), Wesdorp et al. (2005) and Hjorth et al. (2014). In our previous works, the ability to estimate bulk Solid Fat Content (SFC) in different temperatures and the melting point for blends of fats and oils with theoretical composition in triacylglycerols was the major concern (Teles dos Santos et al., 2013, 2014, 2016). The fatty acid and, most important, the triacylglycerol composition determines the physicochemical properties of such systems and these properties can be tailored by preparing blends (oils + fats), which allow them to be more broadly employed. In this article, we intend to highlight the usefulness of computational simulations of melting curves to explore innovative fats and oil mixtures. Coupled with experimental procedures, this methodology can speed up products design. A case study using Amazonian fats and oils is presented.

\section{Models}

\subsection{Computational generation of TAG data from FA data}

The first step is to generate triacylglycerol composition from fatty acids data by combinatorial analysis. Two models can be used:

- the random distribution of fatty acids in the glycerol (no preference to position sn-1,3 and sn-2 of glycerol);

- no random distribution (there is a preference for fatty acids sterification position in the glycerol).

For the first model, only bulk fatty acids composition is necessary as input data. For the second one, the terminal or middle position quantity for each fatty acid is necessary. In this work, only the first model was used, as repartition of fatty acids in terminal positions 1,3 and middle position 2 was not available. To better represent natural products, model 2 is recommended and some inaccuracy of the predictions in this work is expected due to this simplification. Thus, this work generates all possible TAGs from fatty acids that account for $95 \%$ of the total mass, as described in details in our previous work (Teles dos Santos et al., 2013). Figure 1 illustrates the methodology over four generic fatty acids A, B, C and D.

\subsection{Solid-liquid equilibrium and thermodynamic model}

The goal is to estimate the Solid Fat Content (SFC) in a given temperature from fatty acids data. This thermodynamic solid-liquid equilibrium (SLE) problem was solved using the minimum of the Gibbs free energy as a criterion for phase equilibrium (Prausnitz et al., 1999). The problem is the type of nonlinear programming (NLP) that aims to minimize the Gibbs free energy function $(\boldsymbol{G})$, subject to linear material balance constraints. The non-idealities in solid phase are taking into account by activity coefficients. For this purpose, the 2-sufixe Margules model was chosen, as there are experimental database in triacylglycerols that allows computing the interaction parameters between a pair of TAGs $i$ and $j$ (Aij) (Wesdorp et al., 2005). For each TAG present in the mixture (see Fig. 1), two properties are required: melting temperature and melting enthalpy. A program developed in FORTRAN 90 includes a set of experimental data and uses group contribution methods (Zeberg-Mikkelsen and Stendby, 1999) to estimate the values that are not available in the experimental dataset. For a more complete description of the algorithms and methods used, the reader must consult the previous works of the authors (Teles dos Santos et al., 2013, 2014, 2016).

\subsection{Solution Approach}

The NLP problem was implemented in GAMS v.23 (GAMS Development Corporation, 2010) using a generalized reduced gradient method (CONOPT 3 solver). The optimization step was then coupled with the main program written in FORTRAN 90 (using batch files) that handles the calculation of interaction parameters, melting temperature, melting enthalpy and the generation of triacylglycerols from fatty 


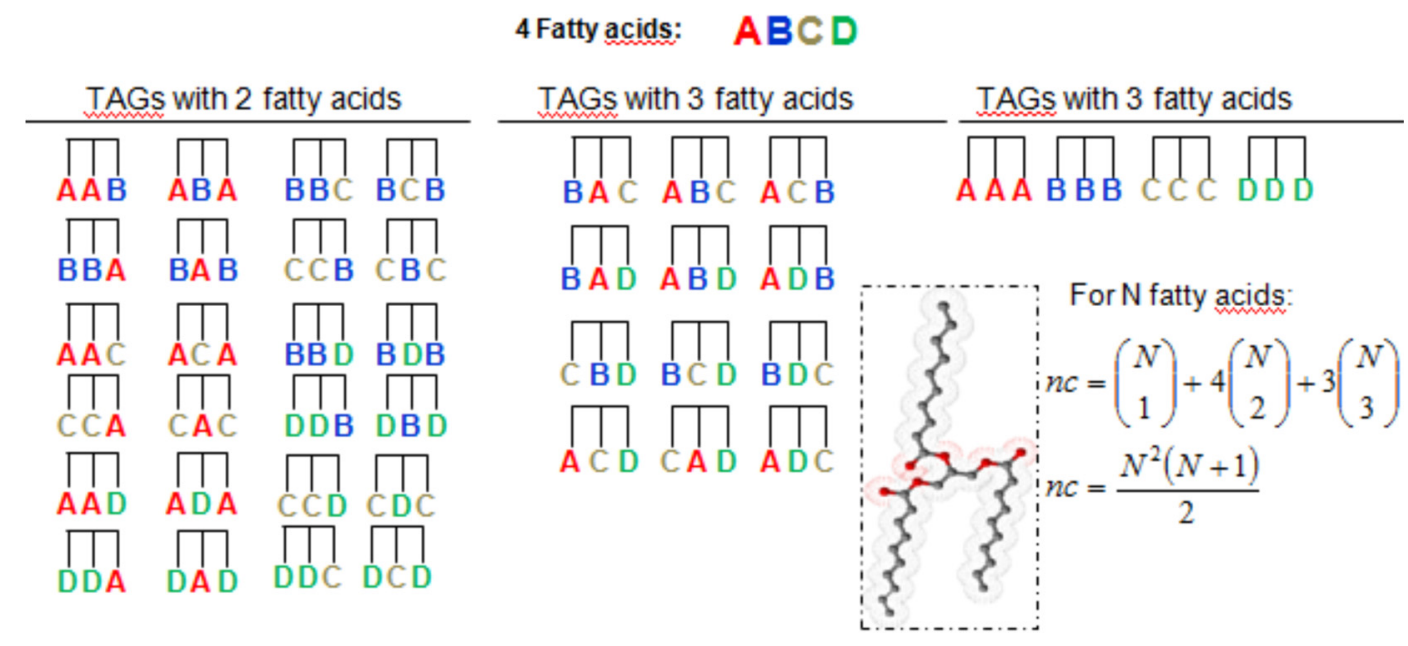

Fig. 1. Computational generation of triacylglycerol composition from fatty acids input data.

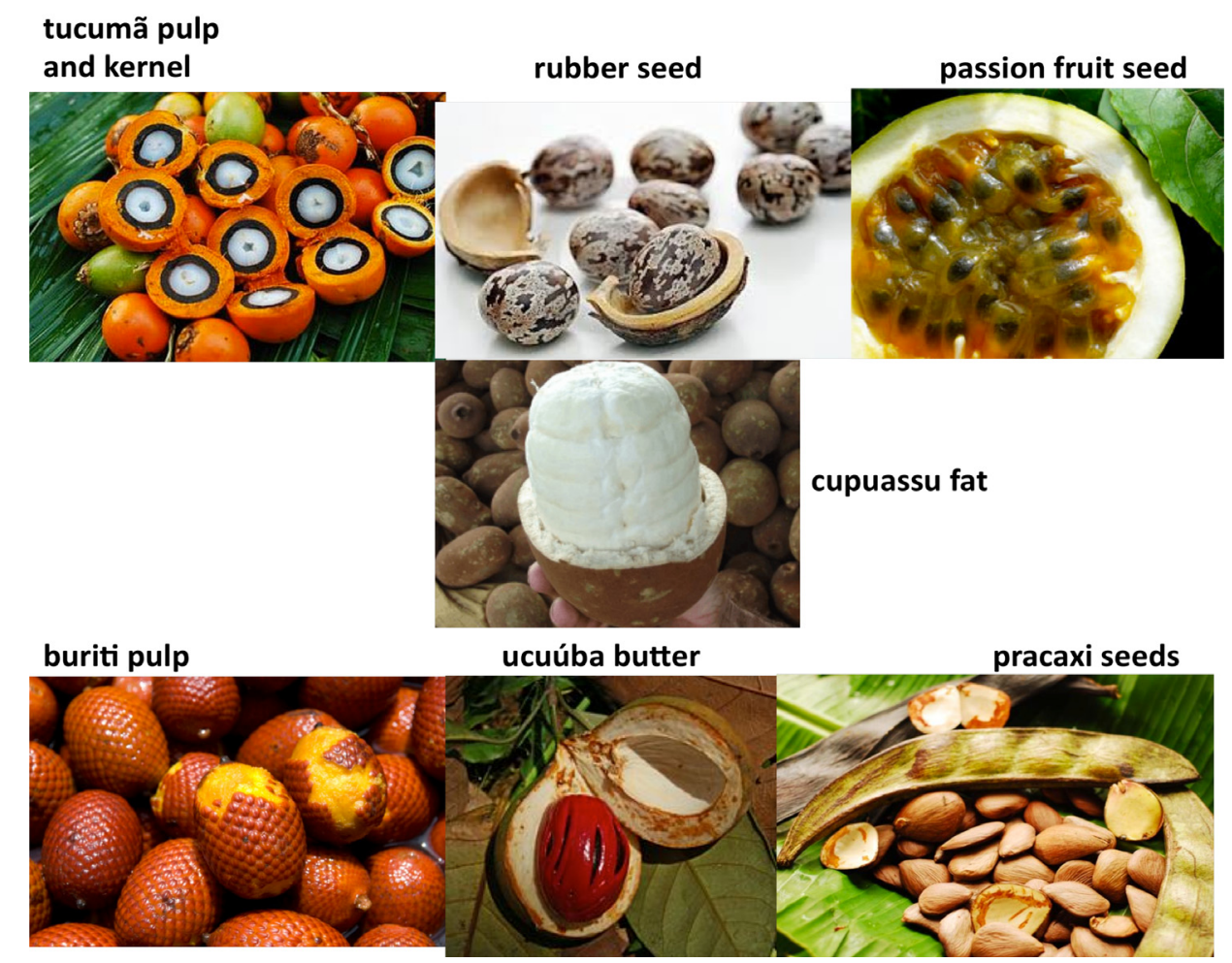

Fig. 2. Different Amazonian sources of oils and fats.

acids data. The computational time required for the whole melting curves varied from 10 seconds (single oils and fats) to 25 seconds (blends), on a personal computer with an Intel (R) CoreTM i7-3770 processor with 8 GB of RAM. To estimate the SFC in a particular polymorphic form, the molar fraction of all TAGs in the other two polymorphic forms is set to zero. All results of this work refers to the $\beta$ ' solid state. We assume, as in Won (1993), that all the triglyceride constituent molecules exhibit the same polymorphic behavior in one phase. Once the number of mols of each TAG in each phase is determined, the $\mathrm{SFC}$ is computed for a given temperature (SFC(T)) and the problem is solved again for a higher temperature $(\mathrm{T}+\Delta \mathrm{T})$ until a whole melting curve is obtained.

\section{Case study: Amazonian oils and fats}

Nine oils and fats typical from Amazonian region were chosen to illustrate the methodology: tucumã pulp and kernel oils (Astrocarium vulgare Mart.), rubber seed oil (Hevea brasiliensis), passion fruit oil (Passiflora edulis), buriti pulp oil (Mauritia flexuosa Mart.), ucuúba butter (Virola surinamensis), pracaxi seeds oil (Pentaclethra macroloba), cupuassu fat (Theobroma grandiflorum) and palm stearin. Their fatty acids composition were gathered from Pardauil et al. (2017) and Bezerra et al. (2017). Then, the thermal properties (melting point and SFC) were predicted, as well for some binary blends. The raw materials from which these oils and fats are extracted are shown in Figure 2. 
Table 1. Theoretical triacylglycerol composition of tucuma kernel oil.

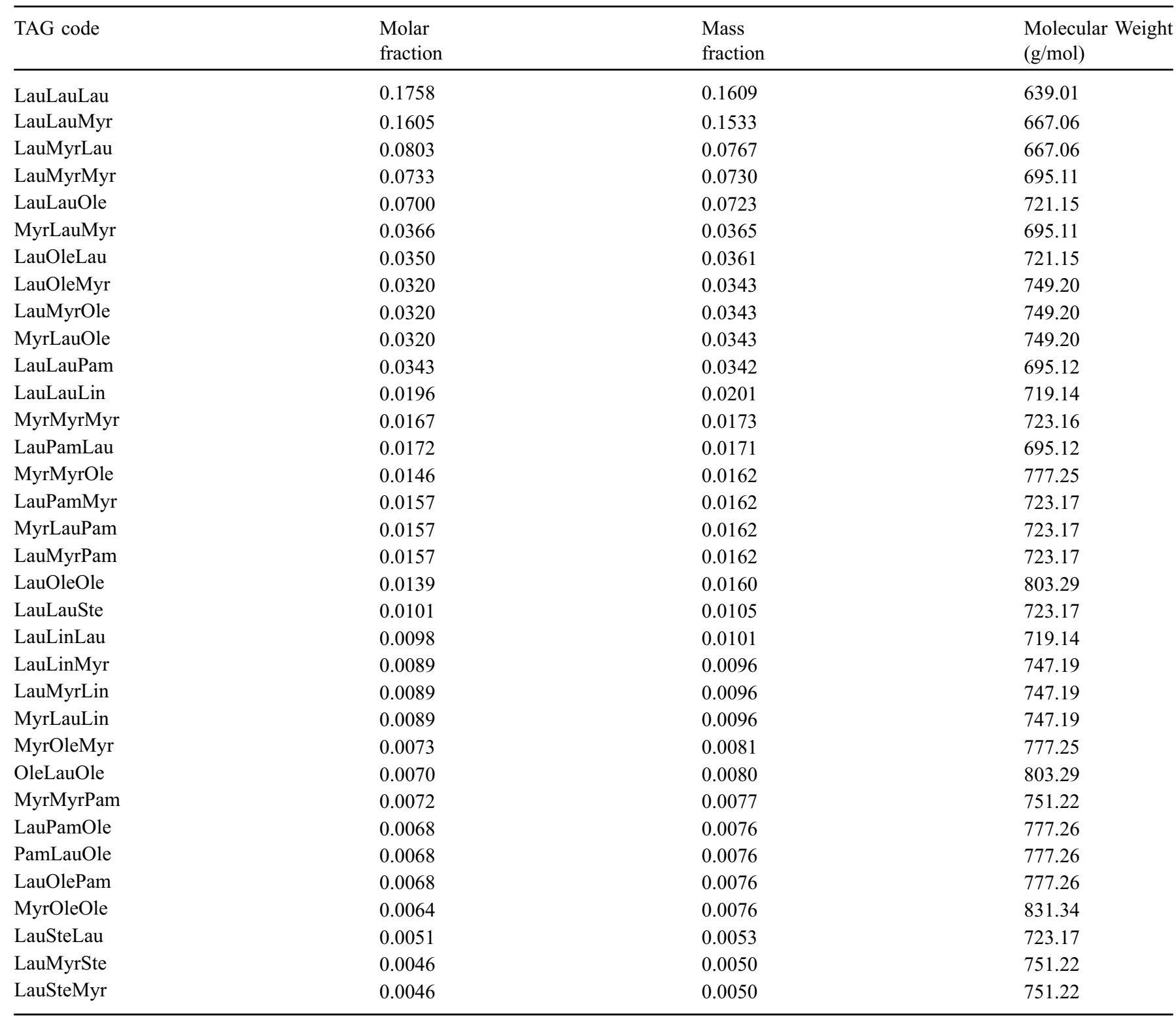

TAG: triacylglycerol; Lau: C12:0; Myr: C14:0; Pam: C16:0; Ste: C18:0; Ole: C18:1; Lin: C18:2.

\subsection{Single oils and fats}

The results of the methodology described in section 3.1 are exemplified in Table 1, where the theoretical triacylglycerol composition of tucuma kernel oil composed by 34 TAGs is shown. The whole TAG composition of all oils, fats and blends used in this study is available upon request. The whole melting curves from computational predictions are shown in Figures $3-5$ and the comparison between experimental and predicted melting points is shown in Table 2.

We can observe that the simulated melting curves follow the expected general behavior of fats and oils: the higher the saturation level, the higher the melting point. Indeed, according to the fatty acids composition, the most saturated fats are ucuuba butter, tucuma kernel, palm stearin and cupuassu fat, all of them having predicted melting points higher than $40{ }^{\circ} \mathrm{C}$ (see Tab. 2 and Figs. 3 and 4). On the other hand, oils with high level of unsaturated fatty acids, mainly oleic, linoleic and linolenic acids, have lower melting points and lower solid fat content in a given temperature. This can be observed though Figures 3-5 and Table 2.

Ucuuba butter has $92.4 \%$ in saturated fatty acids, while tucuma kernel oil has $81.1 \%$. This is directly observed in the simulated melting curve in Figure 4, in which the ucuuba butter has higher SFC in the whole melting range compared to tucuma kernel oil. The final melting point was predicted with good agreement (Tab. 2): the larger absolute error was found to palm stearin $\left(9.2^{\circ} \mathrm{C}\right)$ and an average absolute error of $4.5^{\circ} \mathrm{C}$ was obtained. 


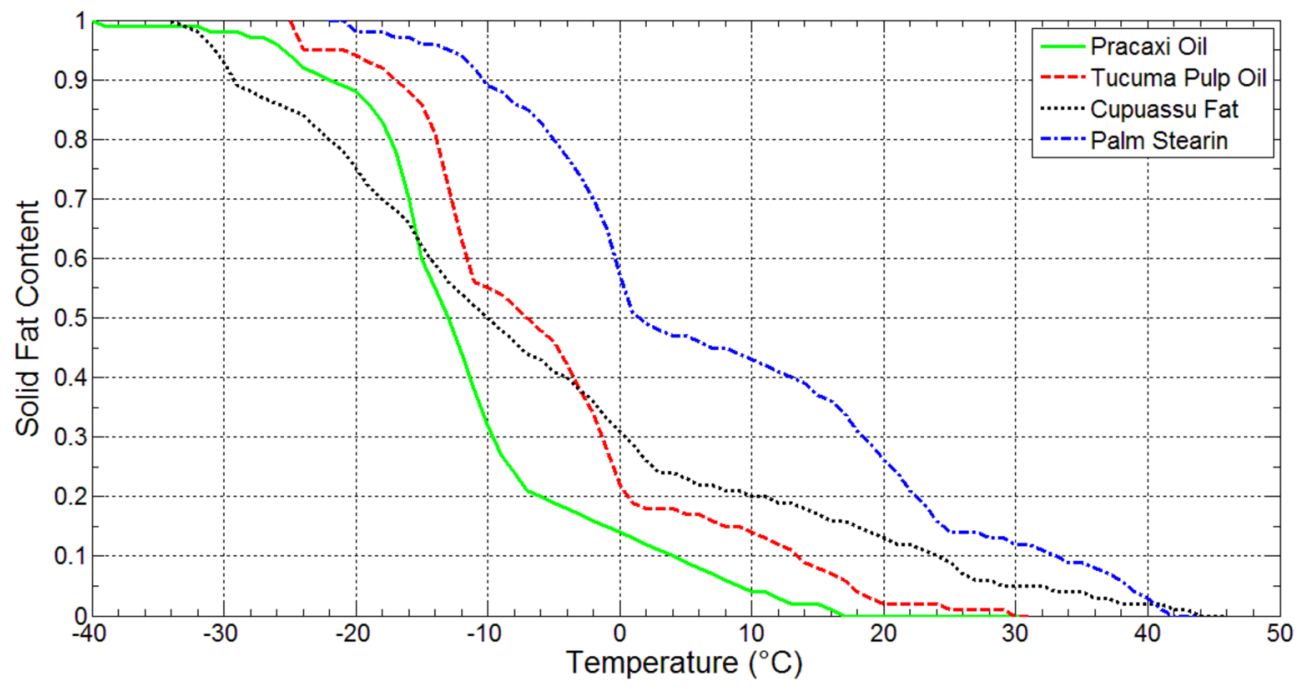

Fig. 3. Melting curves (in silico) for Tucuma Pulp Oil, Pracaxi Oil, Cupuassu Fat and Palm Stearin.

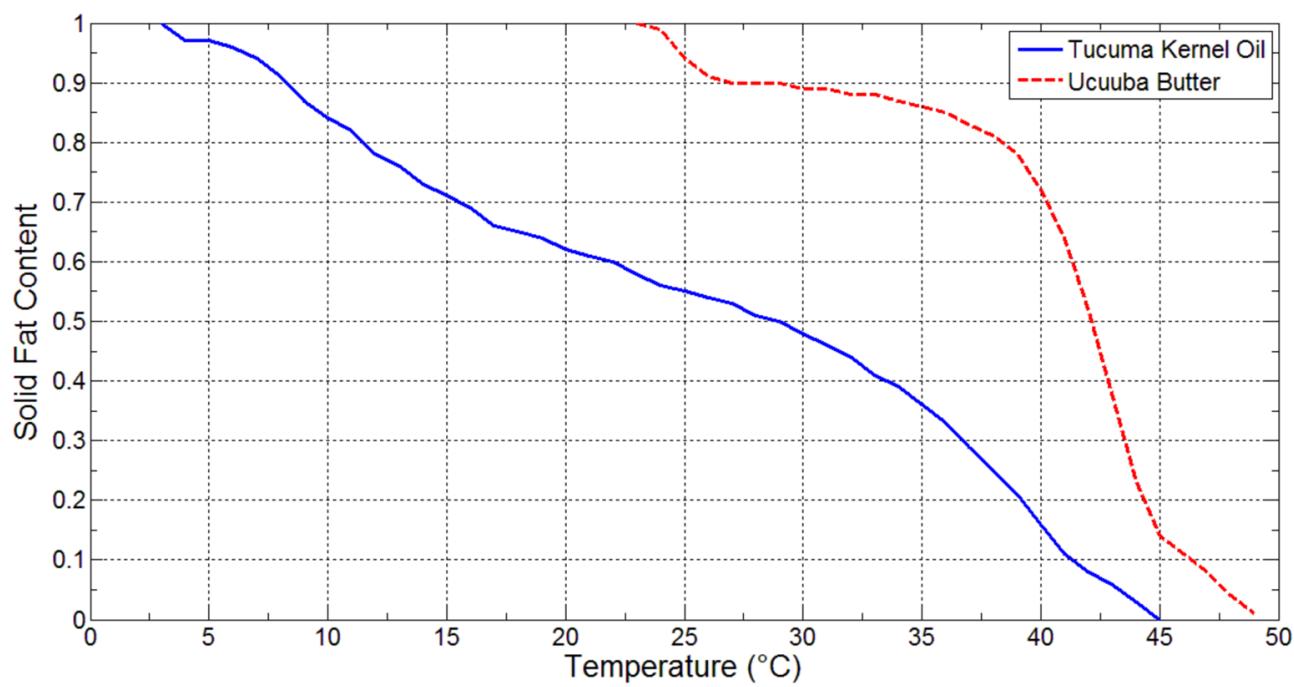

Fig. 4. Melting curves (in silico) for Tucuma Kernel Oil and Ucuuba Butter.

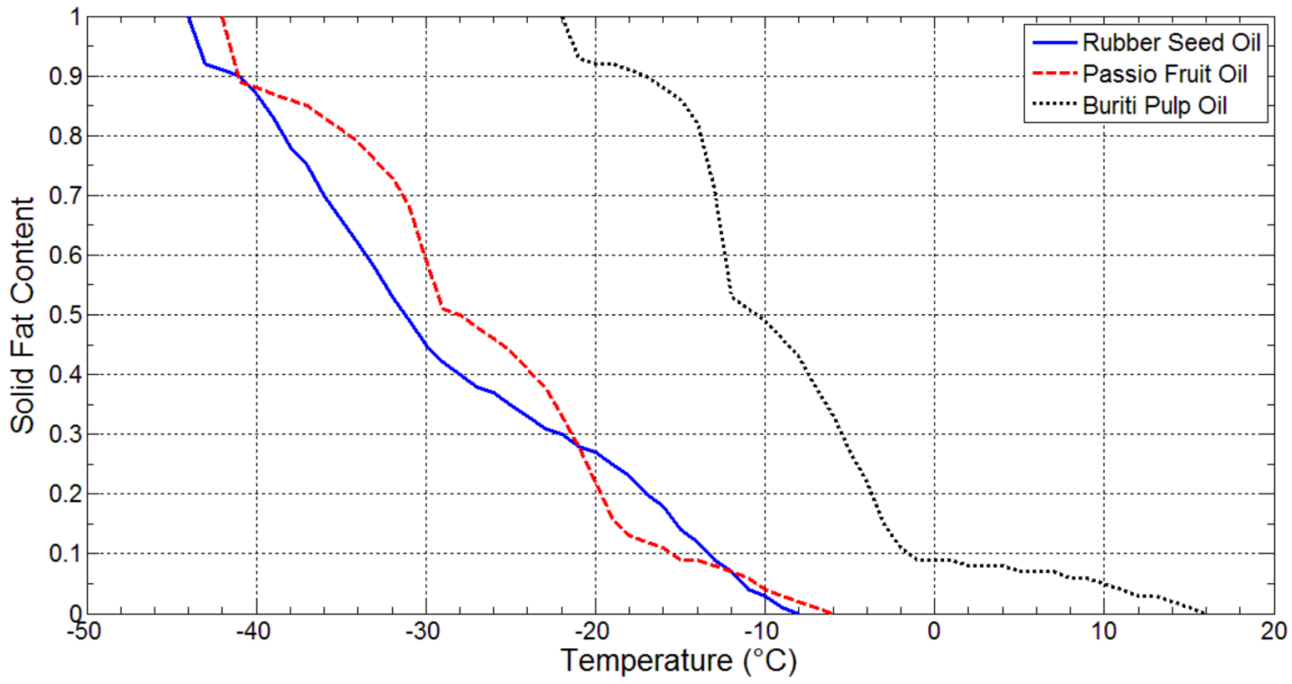

Fig. 5. Melting curves (in silico) for Rubber Seed Oil, Passion Fruit Oil and Buriti Pulp Oil. 
Table 2. Experimental vs. predicted melting points.

\begin{tabular}{|c|c|c|c|c|c|c|}
\hline Name & \multicolumn{2}{|c|}{ Melting Point $\left({ }^{\circ} \mathrm{C}\right)$} & Absolute error $\left({ }^{\circ} \mathrm{C}\right)$ & SFA & MUFA & PUFA \\
\hline Tucuma pulp oil & $31.8^{\mathrm{a}}$ & 30.0 & 1.8 & 28.5 & 63.2 & 6.0 \\
\hline Rubber seeds oil & $-11.2^{\mathrm{a}}$ & -8.0 & 3.2 & 13.5 & 27.0 & 56.0 \\
\hline Passion fruit oil & $-9.8^{\mathrm{a}}$ & -6.0 & 3.8 & 14.1 & 17.1 & 71.5 \\
\hline Pracaxi oil & $18.5^{\mathrm{d}}$ & 16.0 & 2.5 & 41.2 & 44.3 & 4.3 \\
\hline Cupuassu fat & $38.1^{\mathrm{b}}$ & 44.0 & 5.9 & 42.2 & 41.6 & 16.7 \\
\hline \multirow[t]{2}{*}{ Palm stearin } & $51.2^{\mathrm{b}}$ & 42.0 & 9.2 & 51.9 & 40.1 & 7.9 \\
\hline & & Average & 4.5 & & & \\
\hline
\end{tabular}

SFA: saturated fatty acids; MUFA: monounsaturated fatty acids; PUFA: polyunsaturated fatty acids.

a Pardauil et al., 2017

b Bezerra et al., 2017

c Albuquerque et al., 2005

d http://www.amazonoil.com.br/en/

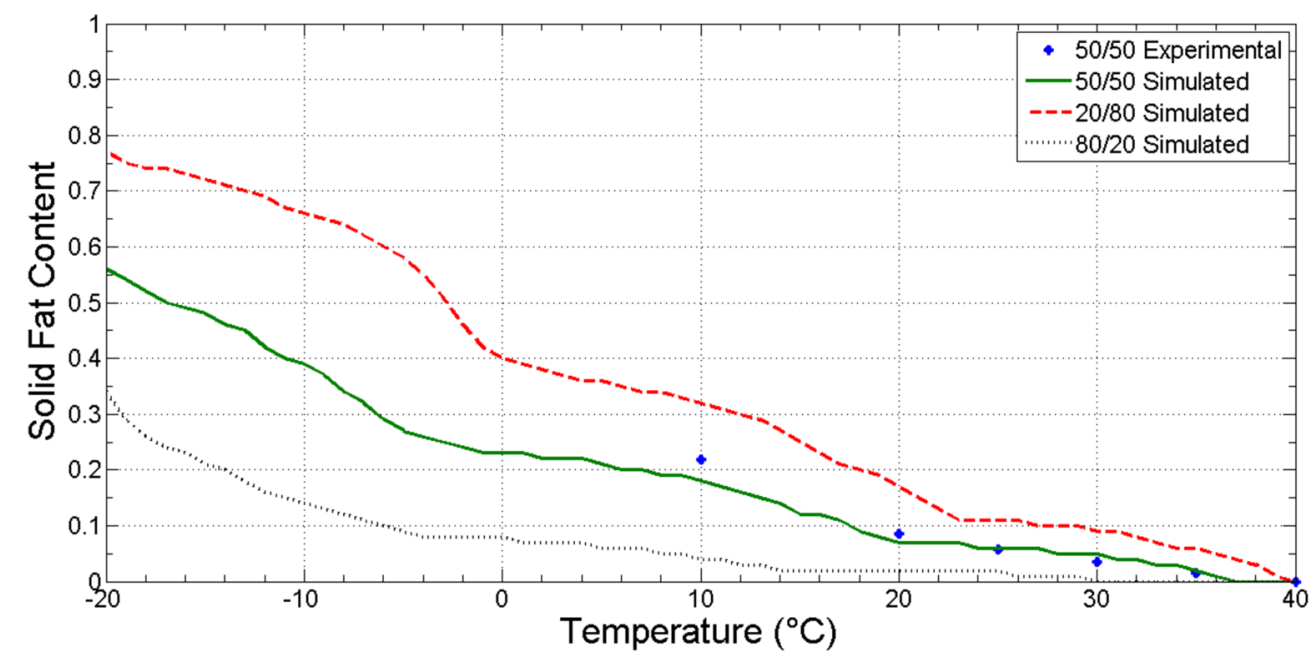

Fig. 6. Melting curves (in silico) for Passion Fruit Oil and Palm Stearin binary blends at different proportions.

\subsection{Binary blends}

The simulated melting curves for 50/50, 20/80 and 80/20 binary blends of passion fruit oil and palm stearin are presented in Figure 6. To verify the accuracy of the model, six experimental points reported by Bezerra et al. (2017) for the $50 / 50$ blend are also shown. These results highlight two usefulness of the methodology:

- it allows evaluating the SFC in temperatures not evaluated experimentally $\left(\mathrm{T}<10^{\circ} \mathrm{C}\right)$;

- it allows evaluating the SFC in mass fraction of each oil/fat in the blend not evaluated experimentally (namely, 20/80 and $80 / 20$ ).
Figure 6 also reveals the ability of the model to take into account the effect of the higher melting fat in the SFC of the blend. In a given temperature, the higher the amount of the high melting fat (palm stearin), the higher the SFC.

It can be observed a good agreement between experimental and predicted SFC for the 50/50 blend. An average absolute error of 1.3 over the 6 experimental points was observed. Also, the experimental SFC (from Bezerra et al. (2017)) and the predicted ones (this work) are shown in Table 3 for other 50/50 blends using other fats and oils. When the complete set of 24 experimental SFC data is considered, the average absolute error of the model is 3.8 (see Tab. 3). 
Table 3. Experimental vs. predicted solid fat content for 50/50 binary blends. Experimental data: Bezerra et al. (2017).

\begin{tabular}{|c|c|c|c|c|c|c|c|}
\hline \multicolumn{4}{|c|}{ Pracaxi Oil/Palm Stearin } & \multicolumn{4}{|c|}{ Pracaxi Oil/Cupuassu Fat } \\
\hline $\begin{array}{l}\text { Temperature } \\
\left({ }^{\circ} \mathrm{C}\right)\end{array}$ & $\begin{array}{l}\text { SFC } \\
\text { experimental }\end{array}$ & $\begin{array}{l}\text { SFC } \\
\text { predicted }\end{array}$ & $\begin{array}{l}\text { Absolute } \\
\text { error }\end{array}$ & $\begin{array}{l}\text { Temperature } \\
\left({ }^{\circ} \mathrm{C}\right)\end{array}$ & $\begin{array}{l}\text { SFC } \\
\text { experimental }\end{array}$ & $\begin{array}{l}\text { SFC } \\
\text { predicted }\end{array}$ & $\begin{array}{l}\text { Absolute } \\
\text { error }\end{array}$ \\
\hline 20 & 7.3 & 9.0 & 1.7 & 20.0 & 8.7 & 5.0 & 3.7 \\
\hline 25 & 4.9 & 7.0 & 2.1 & 25.0 & 0.0 & 3.0 & 3.0 \\
\hline \multirow[t]{2}{*}{40} & 0.0 & 0.0 & 0.0 & 40.0 & 0.0 & 1.0 & 1.0 \\
\hline & & Average & 1.9 & & & Average & 6.6 \\
\hline \multicolumn{4}{|c|}{ Passion fruit Oil/Palm Stearin } & \multicolumn{4}{|c|}{ Passion fruit Oil/Cupuassu Fat } \\
\hline $\begin{array}{l}\text { Temperature } \\
\left({ }^{\circ} \mathrm{C}\right)\end{array}$ & $\begin{array}{l}\text { SFC } \\
\text { experimental }\end{array}$ & $\begin{array}{l}\text { SFC } \\
\text { predicted }\end{array}$ & $\begin{array}{l}\text { Absolute } \\
\text { error }\end{array}$ & $\begin{array}{l}\text { Temperature } \\
\left({ }^{\circ} \mathrm{C}\right)\end{array}$ & $\begin{array}{l}\text { SFC } \\
\text { experimental }\end{array}$ & $\begin{array}{l}\text { SFC } \\
\text { predicted }\end{array}$ & $\begin{array}{l}\text { Absolute } \\
\text { error }\end{array}$ \\
\hline 25 & 5.7 & 6.0 & 0.3 & 25.0 & 0.0 & 2.4 & 2.4 \\
\hline 30 & 3.5 & 4.5 & 0.9 & 30.0 & 0.0 & 1.9 & 1.9 \\
\hline 35 & 1.5 & 1.8 & 0.3 & 35.0 & 0.0 & 1.2 & 1.2 \\
\hline \multirow[t]{2}{*}{40} & 0.0 & 0.0 & 0.0 & 40.0 & 0.0 & 0.4 & 0.4 \\
\hline & & Average & 1.3 & & & Average & 5.3 \\
\hline
\end{tabular}

When oils and fats of different compositions are mixed, a linear evolution of SFC vs. composition can occur and the blend mixture behaves as ideal. In other cases, the SFC of the blend may be lower than the weighted average of the component fats (Braipson-Danthine and Deroanne, 2006). Thus, the SLE thermodynamic method is a suitable procedure to make such predictions, despite the nature of the fats.

\section{Conclusions}

Coupling experimental data, thermodynamic models and computational tools can reduce time and cost in the evaluation of innovative fats and oils. As the solid fat content is a key property that determines the application of a fat/oil, the possibility to estimate it in silico can orient experiments through the most promising blends. Despite the simplified model of random distribution of fatty acids, the model is able to identify qualitatively the general behavior of higher saturated fatty acids, higher melting points and SFC. Also, in quantitative terms, the average absolute error was kept within small values. The limitations of this methodology is that it does not consider other molecules than triacylglycerols and the presence of unusual fatty acids, such as those with branched chains, can lead to large deviations from the real solid-liquid equilibrium state.

\section{References}

Albuquerque MLS, Guedes I, Alcantara Jr P, et al. 2005. Characterization of Buriti (Mauritia flexuosa L.) oil by absorption and emission spectroscopies. J Braz Chem Soc 16: DOI: 10.1590/ S0103-50532005000700004.
Bezerra CV, Rodrigues AMC, Oliveira PD, et al. 2017. Technological properties of amazonian oils and fats and their applications in the food industry. Food Chem 221: 1466-1473.

Braipson-Danthine S, Deroanne C. 2006. Determination of solid fat content (SFC) of binary fat blends and use of these data to predict sfc of selected ternary fat blends containing low-erucic rapeseed oil. JAOCS 83(7): 571-580.

Bruin S, Jongen ThRG. 2003. Food process engineering: The last 25 years and challenges ahead. Compr Rev Food Sci Food Saf 2: $41-81$.

César AS, Almeida FA, Souza RP, et al. 2015. The prospectsofusing Acrocomiaaculeata (macaúba) anon-edible biodiesel feedstock in Brazil. Renew Sustain Energy Rev 49: 1213-1220.

Coutinho DJG, Barbosa MO, Souza RJC, et al. 2016. Comparative study of the physicochemical properties of FAME from seed oils of some native species of brazilian Atlantic forest. J Am Oil Chem Soc 93: 1519-1528.

GAMS Development Corporation, 2010. General Algebraic Modeling System (GAMS) Release 23.1.

Hjorth JL, Miller R, Woodley JM, et al. 2014. Thermodynamic modeling of multi-phase solid-liquid equilibria in industrial-grade oils and fats. J Am Oil Chem Soc 92: 17-28.

Jahurul MHA, Zaidul ISM, Norulaini NAN, et al. 2013. Cocoa butter fats and possibilities of substitution in food products concerning cocoa varieties, alternative sources, extraction methods, composition, and characteristics. J Food Eng 117: 467-476.

Lipp M, Anklam E. 1998. Review of cocoa butter and alternative fats for use in chocolate-Part A. Compositional data. Food Chem 62: 73-97.

Maximo GJ, Costa MC, Coutinho JAP, et al. 2014. Trends and demands in the solid-liquid equilibrium of lipidic mixtures. $R S C$ Adv 4: 31840-31850. 
Pardauil JJR, Molfetta FA, Braga M, et al. 2017. Characterization, thermal properties and phase transitions of amazonian vegetable oils. J Therm Anal Calorim 127: 1221-1229.

Pinho RS, Oliveira AFM, Silva SI. 2009. Potential oilseed crops from the semiarid region of northeastern Brazil. Bioresource Tech 100: 6114-6117.

Prausnitz JW, Lichtenthaler RN, de Azevedo GE. 1999. Molecular thermodynamics of fluid phase equilibria, 3rd ed. New York: Prentice-Hall.

Teles dos Santos M, Gerbaud V, Le Roux GAC. 2013. Modeling and simulation of melting curves and chemical interesterification of binary blends of vegetable oils. Chem Eng Sci 87: 14-22.

Teles dos Santos M, Gerbaud V, Le Roux GAC. 2014. Beyond biofuels: economic opportunities, recent advances and challenges in property modeling for vegetable oils. Green Process Synth 3: 401-410.
Teles dos Santos M, Gerbaud V, Le Roux GAC. 2014. Solid fat content of vegetable oils and simulation of interesterification reaction: Predictions from thermodynamic approach. J Food Eng 126: 198-205.

Teles dos Santos M, Viana IS, Ract JNR, Le Roux GAC. 2016. Thermal properties of palm stearin, canola oil and fully hydrogenated soybean oil blends: coupling experiments and modeling. J Food Eng 185: 17-25.

Wesdorp LH. et al. 2005. Liquid-multiple solid phase equilibria in fats: theory and experiments. In: Marangoni, A.G. (Ed.), New York: Fat Crystal Networks, Marcel Dekker, pp. 481-709.

Won KW. 1993. Thermodynamic model of liquid-solid equilibria for natural fats and oils. Fluid Phase Equilib 82: 261-273.

Zeberg-Mikkelsen CK, Stendby EH. 1999. Predicting the melting points and the enthalpies of fusion of saturated triglycerides by a group contribution method. Fluid Phase Equilib 162: 7-17.

Cite this article as: Santos MTd, Morgavi P, Roux GACL. 2018. Exploring amazonian fats and oils blends by computational predictions of solid fat content. OCL 25(1): D107. 